\title{
Threshold Effect of the Environmental Regulation on the Regional Technology Innovation
}

\author{
Dahua KANG \\ College of Economics \\ Jinan University \\ Guangzhou City, Guangdong Province, China
}

\begin{abstract}
Promoting technology innovation of enterprises through the environmental regulation is the key factor to deal the relationship between economic growth and environmental regulation. All previous literatures considered the intensity of environmental regulation and technology innovation is linear relationship. But we hold the result shows that the intensity of environmental regulation and technology innovation of enterprises is in accordance with the " $U$ " shape. The innovation effect of environmental regulation also depends on the variable of economic development level, which, however, has double thresholds. The higher threshold the economic development crossed, the clearer promotion of environmental regulation on technical innovation will be. This thesis has constructed the mathematical model between the intensity of environmental regulation and technology innovation of enterprises, and examined China's the nonlinear relationship of environmental regulation and technology innovation on the basis of the assumed regional heterogeneity and determined the optimal level of the environmental regulation.
\end{abstract}

Keywords-environmental regulation; threshold effect; technology innovation; regional impacts

\section{The Mathematical Model ABOUt THE EFFeCt OF ENVIRONMENTAL REGULATION ON TECHNOLOGY INNOVATION}

We assumed that the pollution emissions of enterprises were proportional to output, which means that the more output, the more pollution emissions would be. However, the pollution emissions of enterprises should not exceed the minimum requirements of the government's environmental regulation. The maximum profit is the ultimate goal of enterprises. It was assumed that the profit function of enterprises is $\mathrm{P} \cdot \mathrm{A}(\mathrm{KA}) \mathrm{f}(\mathrm{KP})$ in which $\mathrm{P}$ stands for the commodity price; A (KA) is the production technology of enterprises which lies in on the enterprise's investment on the research and development (KA), and $\mathrm{f}(\mathrm{KP})$ as the maximum output under the specific technology, depends on the enterprise's capital investment (KP ). While under the Hicks' hypothesis of neutral technical progress, the output function of enterprises is $\mathrm{A}(\mathrm{KA}) \mathrm{f}(\mathrm{KP})$ ( Here $\mathrm{F}$ denotes the function). In addition, all markets, including elements and product markets are perfectly competitive market. W (F, E) shows the quantity of an enterprise's pollution emissions, depending on the output $(\mathrm{F})$ and anti-pollution spending $(\mathrm{E})$, and meets the condition that $\mathrm{W}^{\prime}(\mathrm{F}, \bullet)>0$. If $\mathrm{W}^{\prime}(\bullet, \mathrm{E})<0$, W
$'(F, \cdot)>0$, it indicates that the relationship between the output and pollution is increasing, and the more output, the more the more pollution will be. If $\mathrm{W}^{\prime}(\bullet, \mathrm{E})<0$, it shows that the relationship of anti-pollution expenditure and emissions is decreasing and the more anti-pollution, the less pollution will be. Because pollution has negative externality, enterprises must meet the requirements of environmental regulation unconditionally if governments have specified the level of environmental regulations (R).

When a government has set the intensity of environmental regulation, enterprises usually adopt the following two ways to reduce pollution emissions so as to meet the demands for environmental regulation. The first is "effect of technological advances in pollution control", that is, enterprises can handle the pollution directly by the expenses of end pollution control to reduce the current pollution emissions. The second is "to innovative compensation effect", namely, enterprises through the increase of the research and development for the clean technology to increase output and profits, in turn more money will be used for pollution treatment. Therefore, in the process of enterprises' production, the level of technology development (A) and the level of anti-pollution technology(E) determine the size of technical level $\mathrm{T}(\mathrm{A}, \mathrm{E})$, and must satisfy the condition of $\mathrm{T}^{\prime}(\mathrm{A})>0$ and $\mathrm{T}^{\prime}(\mathrm{A}, \mathrm{E})>0$.

Production set can be divided into two parts to distinguish between "effect of technological advances in pollution control" of enterprises and "to innovative compensation effect". One part is a enterprise's total production set $\mathrm{A}(\mathrm{KA}) \cdot \mathrm{f}(\mathrm{KP})$; The other part is pollution set $\mathrm{A}(\mathrm{KA}) \cdot \mathrm{f}(\mathrm{KP})$ with $0<\alpha<1$. $\alpha$ stands for the proportion of anti-pollution in a enterprise's total output and also reflects the enterprise's response degree to the intensity of environmental regulation. According to the above definition, $\mathrm{A}(\mathrm{KA}) \cdot \mathrm{f}(\mathrm{K} \mathrm{P})=\mathrm{E}$. In addition, the pollution (W) lies in an enterprise's total output and anti-pollution expenditure, so the optimal behaviors for the enterprises' pollution and technological innovation are as follows:

(1)

$$
\operatorname{Max} \Pi=\mathrm{P}[\mathrm{A}(\mathrm{KA}) \mathrm{f}(\mathrm{KP})-\alpha \mathrm{A}(\mathrm{KA}) \mathrm{f}(\mathrm{KP})]
$$

s. $t \mathrm{~W}[\mathrm{~A}(\mathrm{KA}) \mathrm{f}(\mathrm{KP}), \quad \mathrm{a} \mathrm{A}(\mathrm{KA}) \mathrm{f}(\mathrm{KP})]=\mathrm{R}$

According to the first order condition of enterprise optimization, we can deduce

$a \mathrm{~W} / a \mathrm{E}=-\alpha \mathrm{W} / \mathrm{a} \mathrm{F}$ 
The above equations mean that: under certain intensity and standards of environmental regulation, the enterprise's optimal choice is to make the increased marginal pollution from production equal to the decreased marginal pollution for pollution control. According to eqution(2), W denotes the emission quantity of enterprises under specified intensity of environmental regulation. Therefore, the variable of environmental regulation can be replaced by quantity of one enterprise's pollution emissions.

The lower intensity of environmental regulation, the higher quantity of a enterprise's pollution emissions will be and vice versa. Moreover, in accordance with the technical function of the enterprise $\mathrm{T}^{\prime}\left(\mathrm{A},{ }^{\prime}\right)>0$, the result can be:

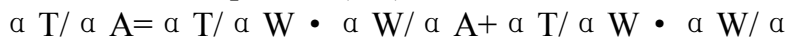

$E \cdot a f>0$ (4)

According to $\alpha \mathrm{W} / \alpha \mathrm{A}=\alpha \mathrm{W} / \alpha \mathrm{F} \cdot \mathrm{f}+\alpha \mathrm{W} / \alpha \mathrm{E} \cdot \alpha \mathrm{f}$, equation (3) and the enterprise' technical function, the result is available:

In line with formula (4), the stronger the intensity of the environmental regulation, the lower the quantity of enterprise's pollution emission will be. If $\mathrm{W} a<0$, which signifies that with the increasing intensity of environmental regulation, at the same time $\alpha$ is also increasing. Thus can be seen that when $\alpha$ ranges from 0 to 0.5 , in accordance with

$[\alpha \mathrm{W} / \alpha \mathrm{F}(1-2 \alpha)] \cdot \mathrm{f}>0$, the result is $\alpha \mathrm{TA} / \alpha \mathrm{W}+\alpha \mathrm{TE} / \alpha \mathrm{W}$ $>0$ and according to $\alpha \mathrm{TE} / \alpha \mathrm{W}<0$, we can get $\alpha \mathrm{TA} / \alpha \mathrm{W}>0$, which indicates that under the weak intensity of environmental regulation, if it was enhanced, the enterprise's pollution emissions will be dropped off and meanwhile the technology innovation tends to fall off. If $\alpha$ ranges from 0.5 to 1 , with $[\mathrm{WF}(1-2 \alpha)] \cdot \mathrm{f}<0$, we can calculate the result that $\alpha \mathrm{TA} / \alpha \mathrm{W}+\alpha \mathrm{TE} / \alpha \mathrm{W}<0$, here $\alpha \mathrm{TA} / \alpha \mathrm{W}$ may be more than 0 or less than 0 . However, if the intensity of environmental regulation is increasing at this stage, that is to say, $\alpha$ is close to 1 , at the same time the enterprise expands spending on pollution control, which indicates that if the intensity of environmental regulation further improved to a more serious stage, and also the pollution emissions further reduced, the results shows that the technology innovation of the enterprise is more obvious. According to the above inference in this thesis, we can get the proposition that in terms of the intensity of environmental regulation, it also shows a "U" shape relationship as well as technology innovation.

\section{THRESHOLD EFFECT OF THE ENVIRONMENTAL REGULATION ON TECHNOLOGY INNOVATION}

\section{A. Threshold panel model}

The above-mentioned mathematical model proves the nonlinear relationship between the intensity of environmental regulation and technology innovation in theory. Then this thesis gave an empirical text on the relationship of them based on empirical data whereas previous literatures did not take the innovation effect among environmental regulations has "threshold effect", which refers that effect of environmental regulation on technology innovation exists several key points, only the economic variables related to regions cross them, can the environmental regulation promote technology innovation. Text methods for the threshold effect often adopt group test and cross term test. Group test should divide the samples into several groups in advance but lack objective and unified standards; Cross term test should build linear model for cross terms but the forms of them is hard to determined. The two methods could not solve apparent test problems for "threshold effect". For this reason, the author employed the panel threshold regression model put forwarded by Hansen. One of its advantage is the threshold value could be evaluated and the internal "threshold effect" could go through significance test. The thought takes one threshold value as an unknown variable into regression model, then constructs a piecewise function and also has a empirical evaluation and inspection of "threshold effect" and correspondent threshold value.

In addition to the threshold value of environmental regulation(ER*), this thesis also selected the index for measuring the economic development level (GDP) as the evaluation object of threshold. In consideration to threshold variables perhaps exist multiple values, therefore, the author built following threshold panel data models respectively which took Er* and GDP as threshold variables, for example formula(5) and (6):

$$
\begin{aligned}
& \operatorname{lnI} \text { it }=\delta+\alpha 1 \ln \mathrm{Er}^{*} \cdot \mathrm{I}(\operatorname{lnEr} * \leqslant \gamma 1)+\alpha 2 \ln \mathrm{Er}^{*} \cdot \mathrm{I}\left(\ln \mathrm{lr}^{*}\right. \\
& >\gamma(1)+\ldots \\
& +\alpha \mathrm{n}+1 \ln \mathrm{Er}^{*} \cdot \mathrm{I}\left(\ln \mathrm{lr}^{*}<\gamma \mathrm{n}\right)+\beta 1 \mathrm{H} \text { it }+\beta 2 \mathrm{M} \text { it }+ \\
& \beta 3 \text { GDP it }+ \text { eit } \\
& (\operatorname{lnGDP} \text { it }>\gamma 1)+\ldots \\
& +\lambda \mathrm{n}+1 \operatorname{lnEr} * \cdot \mathrm{I}(\operatorname{lnGDPit}<\gamma \mathrm{n})+\beta 1 \mathrm{H} \text { it }+\beta 2 \mathrm{M} \text { it }+ \\
& \beta 3 \text { GDP it }+ \text { eit }
\end{aligned}
$$

In the two formulas, $\lambda 1, \lambda 2 \ldots \lambda \mathrm{n}$ are the threshold values to estimate and $\mathrm{I}(\mathrm{g})$ is index function. To inspect threshold effect, the two problems should be solved: The first is to evaluate threshold value and its coefficient; the second is to have a significance test about the threshold effect.

\section{$B$. The result for the effect of environmental regulation on technology innovation}

According to forward model evaluation and inspection methods, we use the panel threshold regression model adopted by Hansen. This thesis had an empirical analysis by Stata12.0 statistic software with its steady evaluation method. We use the 1990-2010 panel data from China. The result is showed in Table 1.

All previous literatures considered the intensity of environmental regulation and technology innovation is linear relationship. Most of them thought that the stronger the intensity of environmental regulation, the more obvious the promotion effect of technology innovation will be. What's more, they called on the intensity of environmental regulation so as to enhance more suggestions for technology innovation. But in accordance with empirical results (Table 1), the effect of environmental regulation on technology innovation is not monotone increasing ( or monotone decreasing ) but exists one "threshold": If the intensity of environmental regulation (Er*) is less than 0.314, its effect on elastic coefficient of technology innovation is obvious 
negative value ( -0.023$)$; when the relationship is in negative correlation, which can restrain technology innovation; If the intensity of environmental regulation (Er*) exceeded the threshold value, its effect on elastic coefficient of technology innovation is obvious positive value ( 0.031), its relationship promotes technology innovation, namely, in terms of intensity dimension, it also shows a " $U$ " shape relationship as well as technology innovation.

Table 1 the threshold value and diameter evaluation

\begin{tabular}{|c|c|c|c|c|}
\hline Parameter & Variable & Estimation & $\mathrm{t}$ value & $\begin{array}{l}\text { Confidence } \\
\text { interval }\end{array}$ \\
\hline $\begin{array}{ll}a & 1\end{array}$ & Er $*<0 . \quad 314$ & -0.023 & -2.05 & $\left(\begin{array}{lll}-0.0420 .045\end{array}\right)$ \\
\hline a 2 & $\operatorname{Er} * \geqslant 0.314$ & 0.031 & 2. 68 & $\left(\begin{array}{lll}-0.0230 .021) \\
(0.03\end{array}\right.$ \\
\hline$\lambda 1$ & GDP $<10065$ & -0.007 & -0.54 & $\left(\begin{array}{llll}-0.01, & 0.03\end{array}\right)$ \\
\hline$\lambda 2$ & $10065 \leqslant \mathrm{GDP}<18910$ & 0.021 & 2. 87 & $\left(\begin{array}{llll}0 . & 014, & 0 . & 058\end{array}\right)$ \\
\hline$\lambda 3$ & $\mathrm{GDP} \geqslant 18910$ & 0.036 & 3. 67 & $\left(\begin{array}{llll}0 . & 032, & 0.078\end{array}\right)$ \\
\hline
\end{tabular}

The reason for the "U" shape between intensity of environmental regulation and technology innovation was researched by the author. The author considered: When a government has set the intensity of environmental regulation, enterprises usually adopt the following two ways to reduce pollution emissions so as to meet the demands for environmental regulation. The first is "effect of technological advances in pollution control", that is, enterprises can handle the pollution directly by the end expenses of pollution control to reduce the current pollution emissions. The second is "to innovative compensation effect", namely, enterprises though the increase of the research and development for the clean technology to increase output and profits, in turn more money will be used for pollution treatment. In short term, although enterprises could reduce pollution emissions or satisfy the requirements of environmental regulation by increasing the expense of end pollution control, but it inevitably cut investment on research and development of clean technology (innovation) and capital. In the long run, it could lower down the emissions at present, but it cannot solve pollution problems fundamentally. So in order to promote the effects of pollution control, enterprises are certain to try to expand the investment on innovating clean technology so as to boost output profits then further satisfy the demands for the pollution control capital. Furthermore, with stronger environmental regulations of government and overly strict standards for enterprises, part of them must retreat form market and the market concentration is further improved, which leads to expand of enterprise scale and advance the core competitiveness of enterprises by innovating technology. With serious intensity of and standards for the environmental regulation, and the decreasing of marginal effects in end pollution control, enterprises will attach importance to research and development in clean technology.

On the above, the "U" shape relationships between the intensity of environmental regulation and technology innovation on mathematic and empirical aspects. As a matter of fact, the effect of environmental regulation on technology is not only influenced by the regulation intensity itself but also with other aspects of "threshold", one of key elements is local economic scale and development level. In Figure 1, different level of economic development will exert an influence on the innovative effects of environmental regulation, that is, there are differences in innovative effects of environmental regulations in different regions. Different from the single threshold for the intensity of environmental regulation, the level of economic development is with double characteristics.

When per capita GDP in regions is below the first threshold (10065.00 Yuan), the elastic coefficient of environmental regulation to technology innovation is -0.007 ; When it ranges during 10,065 to 18,910 Yuan, the maximum elastic coefficient is 0.036 . The above-mentioned results indicate that the developed proves "Porter Hypothesis" that, the higher the level of economic development, the more obvious promotion effects of environmental regulation to technology innovation; while the China's central and western underdeveloped regions do not support "Porter Hypothesis" that, the backwardness of level of economic development inhabits the realization for innovation effects of environmental regulation. This conclusion has enlightened us that : Is there some links between Environmental Kuznets Curve hypothesis and Porter Hypothesis, or to say, whether we can use Environmental Kuznets Curve hypothesis to give reasonable explanation for supporting diversity in different regions of Porter Hypothesis.

\section{CONCLUSION}

This paper has obvious policy implications: we must clearly recognize that the improvement of environmental regulation's intensity does not automatically facilitate but technology innovation. Environmental regulations should embody different features based on actual institution in different regions to avoid mistakes in blind improvement the intensity of environmental regulation. The empirical results show that the implementation for innovation effects of environmental regulation policy depends largely on the level of local economic development. The economic scale in one country or region only reaches to a certain degree, the promotion effects of environmental regulation could be obvious, which interprets the source of different literature empirical results. It is worth mentioning that although the economic scale is a prerequisite for "Porter Hypothesis". To achieve this condition does not rely on extensive growth mainly in realization of thorough change of economic development so to improve the quality of economic 
development, which needs to reform the origin environmental policy and innovate for the system of environmental regulation. In order to continue to promote technology innovation avoid single and fixed static standards for the origin environmental policy, we should pay more attention to revise policies according to the regional development situation and adjust to reasonable level timely. At the same time, environmental policy should be advanced, and positive effects on environmental policy could not be ignored on the excuse of economic backwardness. Although the economic scale in the central and western underdeveloped regions is smaller than threshold value, but we cannot deny the simulating effect of environmental policy to technology innovation. In fact, the promotion effect of environmental policy on technology innovation is always exist and further proved by strengthening the public's environmental protection awareness and economic development. Therefore, these regions must not follow the way of treatment after pollution, that is, attention should be paid to on environmental regulation and policy after economic development.

\section{REFERENCES}

[1] Zhang Cheng, Lu Yang, Guo Lu, Yu Tongshen. The Intensity of Environmental Regulation and the Progress of Production Technology[J].Economic Reasearch. 2011(02)

[2] Huang Ping, Hu Ridong. The Mechanism and Empirical Research for Mutual Promotion Between Environmental Regulation and Technology Innovation of Enterprises [J]. Financial Theory and Practice. 2010(01)

[3] Xu Donglan, Dong Bo. Analysis on the Effects of Environmental Regulation on the Loss of Technical Efficiency and Productive Force[J]. China Population. Resources and Environment. 2009(06)

[4] HansenB. Threshold Effects in Non-dynamic Panels: Estimation, Testing and Inference[J].Journal of Econometrics.1999(2) 